\title{
A PESSOA COM CEGUEIRA E A PRÁTICA DA INCLUSÃO SOCIAL
}

\section{ARTIGO ORIGINAL}

NASCIMENTO, José Alberto Silva do ${ }^{1}$

NASCIMENTO, José Alberto Silva do. A pessoa com cegueira e a prática da inclusão social. Revista Científica Multidisciplinar Núcleo do Conhecimento. Ano. 06, Ed. 10, Vol. 03, pp. 105-119. Outubro 2021. ISSN: 2448-0959, Link de acesso: https://www.nucleodoconhecimento.com.br/psicologia/pratica-da-inclusao, DOI: 10.32749/nucleodoconhecimento.com.br/psicologia/pratica-da-inclusao

\section{RESUMO}

Essa revisão sistemática de literatura foi realizada em bases de periódicos nacionais, entre abril e setembro/2021, utilizando os termos: "história da pessoa com deficiência", "cegueira", "direitos da PcD" e "inclusão social da PcD". Tem a finalidade de investigar a visão histórica da deficiência, destacando a cegueira, buscando conhecer características sobre esta deficiência, os direitos de quem a possui e suas formas de inclusão. Desse modo, tem como questão norteadora: como asseverar a prática da inclusão social acerca da pessoa com cegueira, provida de respeito, igualdade e equidade? O objetivo foi caracterizar a pesquisa e trazer ao leitor o conhecimento sobre as principais dificuldades enfrentadas por essas pessoas na sociedade. No método, utilizaram-se como critérios de seleção: artigos que abordassem a temática sobre a pessoa com cegueira e sua inclusão social. Foram identificados 16 artigos distintos, publicados entre 2004 e 2019, verificou-se que numa sociedade democrática que pressupõe liberdade e igualdade de direitos, medidas já foram tomadas, contudo, há muito a ser feito, dado que o resultado apontou que a causa da problemática está no descaso coletivo quanto as práticas de inclusão em relação as pessoas com cegueira. Já no que se refere às formas de

\footnotetext{
${ }^{1}$ Graduando do curso de psicologia pela Universidade da Amazônia - UNAMA. Bolsista integral pelo programa Universidade para Todos (ProUni). ORCID: https://orcid.org/0000-0003-0747-1705.
}

RC: 98777

Disponível em: https://www.nucleodoconhecimento.com.br/psicologia/pratica-dainclusao 
solução recorrentes, as estratégias apontadas foram: mais investimento na educação, o severo cumprimento da lei e decreto em vigor e a aplicação prática sobre políticas públicas que fazem jus à inclusão e acessibilidade.

Palavras-chave: Pessoa com deficiência, cegueira, inclusão social, atualidade.

\section{INTRODUÇÃO}

O presente artigo tende a esclarecer e também desmistificar o significado de inclusão social da pessoa com deficiência, especificamente da pessoa com cegueira, para esse fim será elucidado sobre a complexidade bem como as dificuldades enfrentadas por esse indivíduo, falando a respeito do tipo de deficiência, de suas necessidades visando sobretudo como vem sendo construída sua relação com a sociedade de forma a expor sua realidade atual, explanando sobre como a práxis do fenômeno inclusão carece ser exercida sob um olhar cuidadoso, adequado e digno, de modo a tornar-se rotina no cotidiano desses cidadãos, descartando qualquer possibilidade de segregação, uma vez que, como afirma Camargo (2017), é provável que o termo inclusão está sendo utilizado de forma inadequada e mal entendida pelo senso comum. Sendo assim, faz-se necessário expressar acerca da pessoa com cegueira na perspectiva sobre a prática da inclusão social para assim proferir mais a respeito de um assunto na qual ainda é pouco explorado em artigos científicos da atualidade.

A partir dessa questão é importante clarificar que ao falar em inclusão se faz referência a uma forma de democratização e socialização, onde não se há espaço para discriminação, intolerância, tampouco para o preconceito, nem sequer a atenuação do termo inclusão a segregação, no sentido de se fazer entender que o indivíduo com cegueira será devidamente incluso socialmente pelo mero fato de ter seu lugar reservado ou seu acesso com prioridade a algo, e que por conta disso devemos entender que este, por sua vez, deverá considerar-se como um cidadão acolhido por direito e assim sentir-se incluso socialmente. Essa conjuntura já não se deve ser aceitável na sociedade contemporânea na qual, de acordo com a autora 
Gimenes et al. (2014) já possuiu por décadas uma visão excludente, segregadora e preconceituosa sobre a pessoa com deficiência ( $P C D)$. Conceitos esses enraizados que em muitas situações perduram até os dias de hoje.

Contudo, este artigo traz a questão sobre como asseverar a prática da inclusão social acerca da pessoa com cegueira, provida de respeito, igualdade e equidade. $O$ objetivo principal é possibilitar ao leitor o conhecimento sobre as principais dificuldades enfrentadas pela pessoa com cegueira na sua relação com o meio social em que vive atualmente. Além disso, discorrer sobre os direitos garantidos por esses sujeitos propondo buscar possíveis soluções que os ajudem na sua qualidade de vida, adquirindo justa participação social como qualquer outro cidadão. $\mathrm{O}$ presente estudo trata-se de uma pesquisa do tipo qualitativa com procedimento através de análises valorativas de literaturas publicados em artigos e revistas, impressos ou eletrônicos, onde o autor é a peça-chave na interpretação, análise crítica e pessoal. Foram pesquisadas bases de dados científicos em periódicos publicados no Scielo, BVS, revistas científicas e sites oficiais do governo federal.

\section{VISÃO HISTÓRICA SOBRE A DEFICIÊNCIA}

A trajetória da pessoa com deficiência foi cruelmente enfrentada, desde o início da humanidade, através da história pode-se conhecer como os fatos ocorreram na vida desse grupo de pessoas ao longo dos tempos, onde vidas foram sacrificadas e desmerecidas meramente pelo fato de terem nascidas ou por terem adquirido essa condição. Neste cenário, Silveira (2013) compreende que é possível entender a situação enfrentada por essas pessoas nos dias atuais a partir de seus antepassados histórico.

De acordo com Aranha (2005) desde o começo da história a sociedade vem tratando as pessoas com deficiência com preconceito e discriminação. Na antiguidade as pessoas que não pertenciam a nobreza sofriam absoluta exclusão. Existiam apenas dois grupos na sociedade da época, sendo os nobres: donos do poder e o povo: o 
qual eram julgados como desumanos. Assim sendo, o povo tinha que trabalhar e quem manufatura eram os nobres.

A mesma autora ainda enfatiza que pela prática social daquele tempo quem não servia para produzir riqueza, nem para guerrear, não servia para mais nada. Nesse contexto, a pessoa considerada incomum era abandonada à própria sorte pelas margens do rio, e tal fato não era considerado crime perante as autoridades daquela época, por conseguinte, não havia problema de natureza ética ou moral (ARANHA, 2005).

Corrêa (2005) refere que nos tempos da antiguidade as pessoas com deficiência eram classificadas como seres anormais, e por esse motivo sofriam rejeição social. Aranha (2008 apud OLIVEIRA, 2010, p. 28), ressalta: "a deficiência, nessa época, inexistia enquanto problema, as crianças que apresentavam deficiência imediatamente detectáveis, eram expostas no rio, na floresta ou no deserto, abandonada ao relento, até a morte".

Os romanos no início da Era Cristã estabeleceram através de leis, práticas de asfixia e de afogamento dos recém-nascidos "mal constituídos", "débeis" ou "anormais" e tinham a prevenção como justificativas de seus atos (OLIVEIRA, 2010, p. 28).

Já na época da Idade Média e com grande influência que exerceu o Cristianismo, o ser humano começou a ser considerado criação divina, devido a esse fato sua morte seria abominável diante dos olhos de Deus. Contudo, esse acontecimento ainda não foi o suficiente para a pessoa com deficiência ser vista com igualdade social, visto que os religiosos associavam o pecado à imperfeição física ou mental, logo, essas pessoas passaram a sofrer segregação (SILVEIRA, 2013).

A mesma autora ainda ressalta que:

A deficiência foi atribuída ora a desígnios divinos, ora à possessão pelo demônio. Por uma razão ou por outra, a atitude principal da sociedade com relação ao deficiente era de intolerância e punição, representada por ações

RC: 98777

Disponível em: https://www.nucleodoconhecimento.com.br/psicologia/pratica-dainclusao 
de aprisionamento, tortura, açoites e outros castigos severos (ARANHA, 1995 apud SILVEIRA, 2013, p. 14).

A classificação entre os seres humanos, a distinção entre as pessoas, as diferenças entre os cidadãos que convivem na mesma sociedade, são situações que ocorrem há muito tempo e esses fatos registrados está acessível a todos e de conhecimento apenas a quem interessa ou a quem convém saber. Pode-se entender que o indivíduo que possui algum tipo de deficiência, ainda sofre opressão por parte de quem deveria estender as mãos e a discriminação impera desde longa data (MAIOR, 2017).

Nesse sentido, o acesso às raízes históricas sobre a pessoa com deficiência permite ao leitor o conhecimento sobre os fatos vividos que a levaram ao enfrentamento de humilhação, discriminação e todo tipo de preconceito possível que resultam em condição de exclusão milenar (OLIVEIRA, 2010).

\section{A DEFICIÊNCIA VISUAL (CEGUEIRA)}

A deficiência trata-se da perda parcial ou total de parte do corpo humano ou de sua função, seja ela física ou psicológica, no qual prejudica a pessoa na execução de atividades comuns do cotidiano de uma forma meramente típica. Dentre os vários tipos de deficiência destaca-se a visual, que pode ser dividida de duas formas, sendo a primeira a baixa visão, que significa haver uma alteração na vista que não se possa necessariamente remediar, e a outra que se trata sobre a cegueira, que significa haver perda total da visão (MEDEIROS et al., 2017).

Estes autores ainda dizem:

Dentre as deficiências, a visual é a que apresenta a maior prevalência na população brasileira, com, aproximadamente, 35,7 milhões de pessoas com dificuldade de enxergar. Dessas, 29,2 milhões apresentam alguma dificuldade; 6 milhões grandes dificuldades; e 528,6 mil não conseguem enxergar de modo algum (MEDEIROS et al., 2017. p. 1,2).

De acordo com a Classificação Internacional de Funcionalidade, Incapacidade e Saúde (CIF) uma deficiência visual, particularmente a cegueira, ocorre quando uma

RC: 98777

Disponível em: https://www.nucleodoconhecimento.com.br/psicologia/pratica-dainclusao 
doença na visão, no qual é um órgão do sentido, deixa de interpretar os estímulos elétricos pelo cérebro, que funciona como um sensor, comprometendo assim a devida realização de todo sistema ocular (CIEZA et al., 2021).

Com base no decreto 5.296 é tido como pessoa com cegueira aquela que tem a percepção minuciosa da visão, sobretudo em seu melhor olho e com o auxílio de correção da vista, equivalente ou inferior a 0,05, melhor dizendo, não importa o grau das lentes que possa usar para ser considerado deficiente visual, a doença em si não define tal situação, mas sim o quanto se alcança de visão na avaliação oftalmológica, mesmo com óculos ou lentes de contato (BRASIL, 2004).

Por Nunes (2008) entende-se que a cegueira pode ser uma condição tanto congênita como adquirida, sendo a primeira uma questão de nascença ou quando a criança perde a visão antes de completar seus 5 anos. Por outro lado, é considerado cegueira adquirida quando se perde a visão a partir desta idade e para ser considerado pessoa cega sua percepção visual deve estar acusando resultado menor que 0,1 , dito que sua a acuidade ocular seja inferior a 20 graus.

Os dados da Organização Mundial de Saúde mostram a existência de aproximadamente 36 milhões de pessoas cegas no mundo, dos quais $90 \%$ são provenientes de regiões consideradas em desenvolvimento/subdesenvolvidas e 217 milhões de pessoas com comprometimento visual moderado a grave. No entanto, segundo dados do IBGE de 2010, no Brasil, das mais de 6,5 milhões de pessoas com alguma deficiência visual, há 528.624 com cegueira (GERMANO et al., 2019).

Para Medeiros et al. (2017) no que se refere à deficiência visual, trata-se de uma situação irreversível da função visual. O sujeito com tal deficiência tem sua funcionalidade comprometida, com prejuízo na capacidade de realização de tarefas. Sendo classificada em categorias que abrangem desde a perda visual leve até a perda total de visão. 
O estudo Global Burden of Disease (GBD) de 2017 classificou a deficiência visual, incluindo a cegueira, (entre todos os comprometimentos à saúde) como sendo a terceira causa de anos vividos com incapacidade (CIEZA et al., 2021).

\section{CONCEPÇÕES DE SEGREGAÇÃO}

É possível compreender que a forma de assistência à pessoa com deficiência em asilos, mesmo assegurando teto e alimentação, é caracterizado como forma de segregação. Nesse caso também serve de proteção à sociedade, na medida em que distancia aquele que incomoda por meio de condutas desaprovadas e antissociais (NERES; CORRÊA, 2008).

Com base no que dizem Silva e Oliveira (2013), mesmo sendo considerada como prática comum no meio social, a exclusão nem sempre foi o único motivo da falta de notoriedade dos indivíduos com alguma deficiência, para alguns só se há uma opção, em vez de sofrerem exclusão social, passam a sofrerem segregação, sendo que para a grande maioria desse grupo, a visibilidade está fora de cogitação.

Na lógica da segregação a razão consiste em viver como o outro e não com o outro. A repartição espacial é a estratégia das práticas de segregação, que visam retirar dos espaços comuns de convivência social as chamadas figuras da segregação, as quais, agrupadas como formas específicas, se tornam segregados, são todos uns como os outros. A extinção de desigualdades se faz de modo em que as diferenças são retiradas da convivência com o meio social dito comum, e consequentemente, a criação de espaços de segregação resulta em que todos os que são constituídos como figuras da segregação são iguais entre si, excluindo assim suas diferenças (FONTENELE, 2018).

As pesquisas acerca da deficiência além de contribuir de forma positiva para a visibilidade social da PcD a favor da inclusão e em combate a atitudes hoje já inadmissíveis, como a segregação, também expande a esfera ética da Psicologia, 
que atua pela integridade da pessoa e sua compreensão como sujeito, independentemente de sua condição humana. (GESSER et al., 2019).

\title{
5. INCLUSÃO SOCIAL, O FENÔMENO QUE PRECISA SER APLICADO
}

O fato de portar qualquer deficiência já é uma condição com muitos desafios na vida de uma pessoa, essa condição se torna muito mais complexa quando a deficiência é causada pela cegueira. Viver em sociedade nesse estado específico requer muita dependência dos videntes, ainda mais quando se vive em localidades sem adaptações para circulação livre de forma segura, dificultando a vida desse grupo de pessoas de tal maneira impedindo sua independência.

Mazzotta e D' Antino (2011), dizem que:

\begin{abstract}
na Europa e nos Estados Unidos da América, nos anos de 1970, a inclusão social das pessoas com deficiência esboçava entre os direitos sociais básicos expressos em importantes documentos legais e normativos. Já a partir da década de 1980, a inclusão social tem se consagrado no mundo ocidental como fator de inspiração em grandes movimentos sociais e ações políticas. Sucessivamente as sociedades democráticas vêm divulgando, discutindo e defendendo a inclusão como direito de todos sobre os diversos espaços sociais (MAZZOTTA; D' ANTINO, 2011, p. 378).
\end{abstract}

A Declaração Universal dos Direitos Humanos amparada e proclamada pela Assembleia Geral das Nações Unidas em 1948, reconhece em seu Artigo 1 que todos os seres humanos nascem livres e iguais em dignidade e direitos, são dotados de razão e consciência e devem agir em harmonia uns aos outros com espírito de fraternidade (BRASIL, 1998).

A Convenção da Organização das Nações Unidas, incorporada à legislação brasileira em 2008, sobre os Direitos da Pessoa com Deficiência, passa a focar na reabilitação, que engloba medidas efetivas e apropriadas para oportunizar que essas pessoas conquistem e conservem o máximo de independência e um repleto condicionamento corporal, mental, social e profissional, bem como plena inclusão e participação em todos os aspectos da vida. (GERMANO et al., 2019).

RC: 98777

Disponível em: https://www.nucleodoconhecimento.com.br/psicologia/pratica-dainclusao 
Quanto a acessibilidade nos espaços sociais, tratando-se sobre as dificuldades e obstáculos enfrentados por pessoas com deficiência sensorial, sobretudo, os cegos, entendido que:

A questão da acessibilidade para os deficientes sensoriais ou com mobilidade reduzida está estabelecida pela Lei no 10.098/2000 e regulamentada pelo Decreto no 5296/2004. Contudo, ainda é possível observar uma enorme dificuldade para que esse público tenha seus direitos assegurados e respeitados. Tanto a lei quanto o decreto preconizam a eliminação de barreiras e obstáculos nas vias públicas a fim de permitir a liberdade de movimento, com segurança e autonomia, aos sujeitos com mobilidade reduzida, assim como mecanismos e técnicas alternativas que possibilitem a comunicação e sinalização às pessoas com deficiência sensorial, além de acesso à informação, ao trabalho, à educação, ao transporte, à cultura, ao esporte e ao lazer. (MONTEIRO, 2012, p. 1).

Baseado em Camargo (2017) nos deparamos com a realização da práxis de inclusão quando é possível notar o cuidado para com o outro a partir da sua real necessidade, de modo a se pensar em soluções que resolva problemas quanto ao trabalho, na educação, de locomoção entre outros fatores que contribuam para o bem-estar social comum a todos. Esse olhar cuidadoso deve partir de profissionais de diferentes áreas de conhecimentos, responsáveis por zelar e que podem contribuir para uma sociedade mais justa, inclusiva e participativa.

No artigo $5^{\circ}$, inciso XV da Constituição Federal deste país assegura-se o direito de ir e vir de todo indivíduo de modo que este possui o direito de circular livremente em qualquer espaço público. No entanto, este mesmo direito é prejudicado e acaba por ser interrompido de seu pleno exercício na medida em que as pessoas se deparam com a precariedade estrutural nas ruas das cidades e no transporte, principalmente por quem necessita de cuidados especiais (DIONÍSIO, 2015).

É necessário a aplicabilidade na prática, sobre o que rege no Estatuto da Pessoa com Deficiência a partir da Lei № 13.146, no Art. 1ำ que institui a Lei Brasileira de Inclusão, na qual assegura, como o próprio termo da lei intitula, a inclusão social destes indivíduos em que a lei se refere, salvo que a verídica integração e 
participação da $\mathrm{PcD}$ em sociedade seja promovida e respeitada de forma fidedigna (BRASIL, 2015).

A PcD também tem garantia de empregabilidade a partir da lei de cotas, como ressalta Gimenes et al (2014):

O emprego das pessoas com deficiência no Brasil está amparado pela Lei 8.213/91, conhecida como lei de cotas. Segundo Art. 93. A empresa que conta com 100 ou mais empregados está obrigada a reservar vaga de $2 \%$ (dois por cento) a $5 \%$ (cinco por cento) dos seus cargos para beneficiários reabilitados ou pessoas com deficiência. As proporções variam de acordo com o número de empregados: de 100 a 200, a reserva legal é de $2 \%$ de 201 a 500 , de $3 \%$, de 501 a 1.000 , de $4 \%$ e acima de 1.001 , de $5 \%$. (GIMENES et al., 2014, p. 4).

Entretanto, é de extrema relevância esclarecer que:

As empresas se tornam verdadeiramente inclusivas na medida em que suas motivações não se restrinjam ao cumprimento da Lei de Cotas e, sim, que se fundamentem na crença de que a contratação de pessoas com deficiência e o consequente atendimento às suas necessidades especiais beneficiam a todos, inclusive as próprias empresas, e refletem conceitos altamente valorizados no Século XXI (SASSAKI, 2006 apud GIMENES et al., 2014, p. 4).

Ademais, o Art. 4ํ da Lei № 13.146, assevera a PcD o mesmo direito que as outras pessoas, no sentido de busca a igualdade material e concreta entre os cidadãos brasileiros, também prevê que esta pessoa não é forçada, caso não seja de sua vontade, concorrer a cotas de vagas destinadas à $\mathrm{PcD}$ em provas de concurso público, podendo assim, como qualquer outro sujeito, candidatar-se a vaga de ampla concorrência. A lei trás essa igualdade com o objetivo de conceber o máximo de autonomia e liberdade ao indivíduo nessa condição, assim usufruir de seus diretos (BRASIL, 2015).

É relevante evidenciar que o âmbito educacional tem significativa contribuição no que favorece ações de inclusão social. De acordo com as autoras Silva e Oliveira (2021) a educação especial, em respeito às diferenças e visando uma sociedade equitativa, encontra-se em contínuas transformações referentes a exclusão social, de modo a promover aberturas de espaços para pessoas com necessidades

Disponível em: https://www.nucleodoconhecimento.com.br/psicologia/pratica-dainclusao 
especiais, a fim de que estas deixam os ambientes onde são segregadas para tomarem lugar em espaços a que são de direito. Para isso, os diversos conceitos relacionados à $\mathrm{PcD}$ vêm sendo repensados ao longo dos anos, posto isto algumas denominações também têm sofrido alterações. Atualmente refere-se a estes como pessoa com necessidades educativas especiais.

No mais, a educação inclusiva trabalha estabelecendo um padrão educacional focado e em plena fidedignidade aos direitos humanos, no qual em seu âmbito considera a igualdade e a diferença fatores moralmente intrínsecos, ou seja, que fazem parte da essência das pessoas, e sua forma de inclusão está voltada com o máximo possível de imparcialidade absoluta (BRASIL, 2008).

Outra autoria segue acrescentando que:

A inclusão na escola seria, então, o processo pelo qual ela se adapta, se transforma para poder inserir em suas classes regulares crianças e jovens portadores de deficiência que estão em busca de seu pleno desenvolvimento e exercício da cidadania. (BRASIL, 1998 apud SILVA; OLIVEIRA, 2013, p. 6).

Portanto, compete dizer o seguinte:

O Brasil é um país onde os problemas sociais vêm sendo redimensionados através de programas e incentivos de políticas públicas de inclusão e reparo às violações dos direitos humanos. Ainda o preconceito e as disparidades sociais contribuem para o declínio do cenário humanístico, cultural, político e econômico. Os direitos humanos podem mudar essa realidade, e a educação é o principal viés para essa transformação, por meio da dignidade da pessoa humana. (BRASIL, 2013, p. 44).

Uma pessoa com uma doença ocular que apresente qualquer tipo de deficiência visual e enfrente barreiras neste contexto, como o fato de não ter acesso a serviços de atendimento oftalmológico ou ajudas técnicas, provavelmente terá entraves muito maiores em seu cotidiano e, portanto, graus mais elevados de incapacidade (CIEZA et al., 2021).

O mesmo relatório esclarece que "Incapacidade refere-se às deficiências, limitações e restrições que uma pessoa com uma doença ocular enfrenta no curso da 
interacção com o seu meio físico, social ou comportamental" (CIEZA et al., 2021, p. 16).

As ações afirmativas como mecanismo de inclusão social de pessoas com deficiência datam menos de meio século no Brasil e enfrenta o desafio de garantir condições de cidadania e equidade para esta parcela da população. (GERMANO et al., 2019).

É esplendido o que Oliveira (2010) pontua em sua obra sobre o empobrecimento adquirido por uma sociedade ao tomar atitudes de exclusão que afetam parte de seus próprios componentes. Por outro lado, se a atuação social, sobre todos os âmbitos, tornar-se cada vez mais benéfica a favor da pessoa com deficiência, certamente resultará numa sociedade melhor, respeitosa, flexível e acolhedora. (DECLARAÇÃO DE MADRI, 2003 apud OLIVEIRA, 2010). Ademais, Buzzi e Dalonso (2019) dizem que o processo de inclusão se dará a partir do avanço do conhecimento sobre o outro, e assim, quanto mais o entendemos, mais próximo dele podemos chegar, a começar da compreensão humana deixamos de enxergar através do que aparentamos ter de diferença e passamos a perceber que as semelhanças são muito maiores.

\section{CONSIDERAÇÕES FINAIS}

Apesar do atravessar dos séculos desde a Antiguidade, a história permite o acesso ao conhecimento sobre como as pessoas com deficiência eram tratadas naquela época, e diante dos fatos relatados aqui, pôde ser identificado que em pleno limiar do século XXI certas semelhanças não são mera coincidência se comparar com muitos descasos ocorridos na atualidade em que se vive. São problemas milenários enfrentados por esse grupo de seres humanos.

Descasos ocorridos há tanto tempo atrás, como a datar do tempo da Idade média ainda se sucedem, porém, de uma outra forma nos tempos modernos da atualidade, comumente pode-se observar, basta sair pelos grandes centros das cidades e se 
colocar por algumas horas no lugar de uma pessoa com cegueira, andar pelas calçadas irregulares sem piso tátil, atravessar as avenidas por faixa de pedestre sem uso de semáforos com sinais sonoros, adentrar aos prédios construídos sem as adaptações estruturais necessárias, usar elevadores com botoeiras de comando sem acompanhamento de signos em Braille e comunicação auditiva, fazer uso de transportes coletivos sem maior autonomia, entre outros fatores. Dessa maneira, percebe-se que o descaso ainda impera dentre muitas situações, tornando a pessoa com cegueira um indivíduo dotado de vulnerabilidade, a depender da ajuda do outro que seja vidente, ou, dependendo do contexto, exposto à própria sorte.

Não se pode negar que desde a época em que a história conta até a atualidade, tivemos alguns avanços, como a criação de leis a favor da PcD, não obstante, numa sociedade democrática que pressupõe liberdade e igualdade de direitos, medidas já foram tomadas, contudo, há muito a ser feito, ainda estamos longe do alcance da inclusão de forma justa a todos. A pessoa com cegueira ainda enfrenta uma série de dificuldades, como por exemplo a de acessibilidade, no simples fato de exercer o direito de ir e vir livremente a lugares comuns, com maior autonomia.

$\mathrm{Na}$ educação e na empregabilidade a criação das leis que asseguram os direitos desses indivíduos por si só ainda não são o suficiente para cessar a exclusão que assombra a dignidade dessas pessoas. Para uma verdadeira inclusão, muitas barreiras precisam ser quebradas, já que ainda há escolas que recusam matrículas de alunos que precisam de acompanhamento especial, também, ainda há casos de empresas que contratam PcD apenas por uma questão de preenchimento obrigatório da vaga ofertada, no entanto, essas pessoas não deixam de sofrer uma realidade de exclusão a partir de diversos fatores, mesmo estando inseridas no mercado de trabalho, a exemplo disso é quando a $\mathrm{PcD}$ não tem a assistência necessária ou suportes adequado para um bom desempenho de sua função, outro exemplo é quando a importância de sua presença é despercebida ou não solicitada por seus superiores em casos de reuniões e tomadas de decisões no trabalho, afetando assim sua qualificação, chegando a causar insatisfação ou até mesmo o abandono da vaga por parte da PcD. Seja em escolas ou em empresas, ainda muito 
se faz uso da justificativa de não ter recursos próprios que possam atender todas as necessidades das pessoas com deficiência ou deixam a entender que se há interesse da $\mathrm{PcD}$ em ocupar naquele lugar uma vaga, que a aceite de qualquer jeito, sem exigências.

No mais, especialmente a pessoa com cegueira, encontra demasiada dificuldade em conseguir vaga no mercado de trabalho, visto que este tipo de deficiência ainda causa muito preconceito, uma vez que ainda há subestimação social quanto a capacidade cognitiva dessas pessoas, causando resistência por parte das empresas, fato este explicado a partir das raízes históricas sobre a deficiência, todavia a luta pela garantia de seus direitos vem crescendo a partir da convivência destes no meio social.

O campo de estudos sobre a deficiência visual, no qual se inclui a cegueira, discorre sobre os conhecimentos necessários para entender tudo sobre este tipo de deficiência, e através do compartilhamento da experiência vivida por pessoas nessa condição torna-se possível entender a complexidade que é sua vida, fato este que tornou indispensável a discussão do assunto aqui produzido.

Contudo, como asseverar a prática da inclusão social acerca da pessoa com cegueira, provida de respeito, igualdade e equidade? Logo, identificou-se os fatores recorrentes que solucionem a problemática em questão, tais como, mais investimento em educação de forma a sanar o empobrecimento que a ignorância traz em seu seio, dissipando a falta de informação e o desconhecimento por parte das crianças, adolescentes e jovens de todas as faixas etárias, seja nos centros de educação, nas escolas, sobretudo no âmbito familiar. Ademais, através do severo cumprimento do Decreto 6.949/09 que assegura o Direito das Pessoas com Deficiência e da Lei № 13.146/15 que institui a Lei Brasileira de Inclusão, ambas vigentes no Poder Judiciário. Além disso, é preciso também aplicações práticas sobre desenvolvimentos de políticas públicas nas quais possibilitem ofertas de proteção social e autonomia a estes cidadãos, sendo necessário também trabalhar na avaliação das estruturas prediais e arquitetônicas no sentido de planejamento e 
adaptações de acordo com as necessidades da $\mathrm{PcD}$, fazer utilização do Braille nas identificações de todos os locais onde a pessoa com cegueira possa ter acesso, implantar piso tátil pela cidade, providenciar faixas de pedestre segura nos semáforos com sinais sonoros, uma vez que uma das maiores dificuldades do indivíduo com cegueira é ter acesso aos veículos de comunicação utilizados diariamente pelos videntes.

Obviamente, seria muito interessante que a inclusão social fosse praticada por todos na mais boa vontade, através do bom senso e com imparcialidade, sem precisar caracterizar como algo obrigatório ou sequer fazer uso de "ameaças" como a aplicação de penalidades contra quem não a cumpre devidamente.

\section{REFERÊNCIAS}

ARANHA, M. S. F. Projeto Escola Viva: garantindo acesso e permanência de todos os alunos na escola: necessidades educacionais especiais dos alunos. 2 ed.

Brasília, 2005. Disponível

em: http://portal.mec.gov.br/seesp/arquivos/pdf/visaohistorica.pdf. Acesso em: 29 abr. 2021.

BRASIL. Declaração Universal dos Direitos Humanos. Brasília, 1998. Disponível em: Declaração Universal dos Direitos Humanos - UNESCO Digital Library. Acesso em: 11 set. 2021.

BRASIL. LEI 13.146. Lei Brasileira de Inclusão da Pessoa com Deficiência. 2015. Disponível em: http://www.planalto.gov.br/ccivil_03/_ato20152018/2015/lei/l13146.htm. Acesso em: 2 ago. 2021.

BRASIL. Política nacional de educação especial na perspectiva da educação inclusiva. $\quad$ Brasília, 2008. Disponível em: http://portal.mec.gov.br/arquivos/pdf/politicaeducespecial.pdf. Acesso em: 11 set. 2021.

BRASIL. Secretaria de Direitos Humanos da Presidência da República. Educação

RC: 98777

Disponível em: https://www.nucleodoconhecimento.com.br/psicologia/pratica-dainclusao 
em Direitos Humanos: Diretrizes Nacionais. Coordenação Geral de Educação em SDH/PR, Direitos Humanos, Secretaria Nacional de Promoção e Defesa dos Direitos Humanos. Brasília, 2013.

BUZZI, F. DALONSO, F. A relação da pessoa com deficiência visual (cegueira e baixa visão) com o processo de ensino aprendizagem no ambiente acadêmico. p. 186-195. Manaus, 2019. Disponível em: Vista do A RELAÇÃO DA PESSOA COM DEFICIÊNCIA VISUAL (CEGUEIRA E BAIXA VISÃO) COM O PROCESSO DE ENSINO APRENDIZAGEM NO AMBIENTE ACADÊMICO (ufam.edu.br). Acesso em: 9 set. 2021.

CAMARGO, E. P. de. Inclusão social, educação inclusiva e educação especial: enlaces e desenlaces. Ciência e Educação, v. 23, n. 1, p. 1-6, Bauru, 2017. Disponível em: SciELO - Brasil - Inclusão social, educação inclusiva e educação especial: enlaces e desenlaces Inclusão social, educação inclusiva e educação especial: enlaces e desenlaces. Acesso em: 7 jul. 2021.

CIEZA, A. KEEL, S. KOCUR, I. MCCOY, M. MARIOTTI, S. P. Light for the World. Relatório mundial sobre a visão. 2021, 166p. Disponível em: (https://apps.who.int/iris/bitstream/handle/10665/328717/9789241516570-por.pdf). Acesso em: 20 jul. 2021.

CORRÊA, M. A. M. Educação Especial. Fundação CECIERJ, v.1, Rio de Janeiro, 2005.

DIONISIO, S.H.R. Direito de ir e vir na sociedade brasileira. Conteúdo Jurídico, Brasília, 2015. Disponível em: https://conteudojuridico.com.br/consulta/Artigos/44280/direito-de-ir-e-vir-nasociedade-brasileira. Acesso em: 11 ago. 2021.

FONTENELE, T. C. B. SOUZA, L. B. de. LIMA, M. C. P. A segregação em Lacan cinquenta anos depois. Psicologia Clínica, vol. 30, n.3, p. 493-505, Rio de Janeiro, 
2018. Disponível em: A segregação em Lacan cinquenta anos depois (bvsalud.org). Acesso em: 4 ago. 2021.

GERMANO, F. A. S. GERMANO, C. S. GERMANO, R. A. GERMANO, J. E. Estudo das causas de cegueira e baixa de visão em uma escola para deficientes visuais na cidade de Bauru. Rev Brasileira de Oftalmologia. 78 f. p. 183-187. Bauru, 2019. Disponível em: https://doi.org/10.5935/0034-7280.20190125. Acesso em: 8 mai. 2021.

GESSER, M. LOPES, P. H. FERREIRA, S. de M. LUZ, J. de O. VERAS, N. C. de O. RAUPP, F. A. NUERNBERG, A. H. MELLO, A. G. de. MOZZI, G. de. BOCK, G. L. K. SILVA, S. C. da. FERREIRA, C. de A. CARNEIRO, M. S. C. (org.). Psicologia e pessoas com deficiência. Conselho Regional de Psicologia de Santa Catarina CRP-12. Florianópolis: Editora Tribo da Ilha. 2019. 96 p.

GIMENES, A. M., BECHARA, M. T., ÁVILA, R. N. P., RODRIGUES, B. C., ARAÚJO, D. C. dos S. A. A dificuldade da inclusão da pessoa com deficiência no mercado de trabalho. 2014. 15 f. Disponível em: A DIFICULDADE DA INCLUSÃO DE PESSOAS COM DEFICIÊNCIA NO MERCADO DE TRABALHO (inesul.edu.br). Acesso em: 2 ago. 2021.

MAIOR, I. M. M. de L. Movimento político das pessoas com deficiência: reflexões sobre a conquistas de direitos. Rev Inclusão Social, v. 10, n. 2, p. 2836. Brasília, 2017. Disponível em: http://revista.ibict.br/inclusao/article/view/4029. Acesso em: 31 jul. 2021.

MAZZOTTA, M. J. S. D' ANTINO, M. E. F. Inclusão social de Pessoas com deficiências e necessidades Especiais: cultura, educação e lazer. Rev Saúde Soc. v.20, n.2, p.377-389. São Paulo, 2011. Disponível em: https://doi.org/10.1590/S0104-12902011000200010. Acesso em: 11 set. 2021.

MEDEIROS, T. M. de; COSTA, K. N. de F. M. COSTA, T. F. da. MARTINS, K. P. DANTAS, T. R. de A. Acessibilidade de pessoas com deficiência visual nos 
serviços de saúde. Rev Enfermagem UERJ, v. 25. Rio de Janeiro, 2017. Disponível em: http://dx.doi.org/10.12957/reuerj.2017.11424. Acesso em: 11 set. 2021.

MONTEIRO, J. L. Os desafios dos cegos nos espaços sociais: um olhar sobre a acessibilidade. 16 f. (IX ANPED SUL) Seminário de Pesquisa em Educação da região Sul. Santa Catarina, 2012. Disponível em: http://www.ucs.br/etc/conferencias/index.php/anpedsul/9anpedsul/paper/viewFile/108 1/649. Acesso em: 26 jul. 2021.

NERES, C. C. CORREAA, N. M. O trabalho como categoria de análise na educação do deficiente visual. Cad. Cedes, vol. 28, n. 75, p. 149-170, Campinas, 2008. Disponível em: https://www.cedes.unicamp.br. Acesso em: 10 set. 2021.

NUNES, S. S. Desenvolvimento de conceitos em cegos congênitos: Caminhos de aquisição do conhecimento. 287 f. Dissertação (Mestrado). Instituto de Psicologia. Universidade de São Paulo. São Paulo, 2004. Disponível em: https://www.teses.usp.br/teses/disponiveis/47/47131/tde-23012007-

075431/publico/conceitoscegos.pdf. Acesso em: 25 jul. 2021.

NUNES, S. S. LOMÔNACO, J. F. B. Desenvolvimento de conceitos em cegos congênitos: caminhos de aquisição do conhecimento. Rev Semestral da Associação Brasileira de Psicologia Escolar e Educacional (ABRAPEE). v. 12, n. 1, p. 119-138. São Paulo, 2008.

OLIVEIRA, L. C. de. Visibilidade e Participação Política: Um estudo no Conselho Municipal da Pessoa com Deficiência em Niterói. 178 f. Dissertação (Mestrado). Pontifícia Universidade Católica do Rio de Janeiro. Rio de Janeiro, 2010. Disponível em: https://doi.org./10.17771/PUCRio.acad.37140. Acesso em: 4 set. 2021.

SILVA, N.S. OLIVEIRA, T.C.B.C. Concepções e paradigmas: da exclusão à inclusão da pessoa com deficiência. 2013. Disponível em: Trabalho_Comunicacao_oral_idinscrito_736_e26a65969cccf3441ecf8a14885ecf6e.p df (editorarealize.com.br). Acesso em: 4 ago. 2021. 
SILVEIRA, A. B. Estigma e preconceito contra as pessoas com deficiência: A mídia e a comunicação organizacional enquanto permeadoras dos processos sociais. 60 f. Trabalho de Conclusão de Curso. Porto Alegre, 2013. Disponível em: https://www.lume.ufrgs.br/handle/10183/77983. Acesso em: 11 jun. 2021.

Enviado: Agosto, 2021.

Aprovado: Outubro, 2021. 